Original Article

\title{
CULTURAL PRACTICES AND BELIEFS ON NEWBORN CARE AMONG MOTHERS IN A SELECTED HOSPITAL OF MANGALORE TALUK
}

\author{
Reshma ${ }^{1} \&$ Sujatha $\mathbf{R}^{2}$ \\ ${ }^{1}$ Lecturer, ${ }^{2}$ Professor \& HOD, Department of Pediatric Nursing \\ Nitte Usha Institute of Nursing Sciences, Nitte University, Deralakatte, M angalore - 575 018, Karnataka, India. \\ Correspondence: \\ Reshma \\ Lecturer, Department of Pediatric Nursing, Nitte Usha Institute of Nursing Sciences, \\ Nitte University, Paneer, Mangalore - 575 018, Karnataka, India. \\ Mobile : +919035091580 E-mail: reshmarzk@gmail.com
}

\begin{abstract}
:
Background: A human infant from the time of birth upto 28 th day of life is called a newborn. Nearly 27 million babies are born in India each year. Every year 4 million babies die in the first month of life in the world and quarter of these takes place in India. A package of essential newborn practices exist in India which has proven impact on reducing mortality. However child birth and neonatal period are culturally important times during which there is strong adhere to traditional practices.
\end{abstract}

Materials and Methods: A descriptive research design was adopted for this study. Purposive sampling method was used to select 157 samples from a selected hospital. Demographic Performa and structured dichotomous questionnaire was used to collect the data from the subject.

Results: The data collected from 157 samples were analyzed using descriptive statistics. (149) 95\% of the mothers have followed oil massage for the baby before bath. (83) $53 \%$ of the mothers have provided home remedies for the baby. (87) $55 \%$ of the mothers were applying ashes, soot, powder, or dry cow dung, (115) 73\% mothers exposed their babies to the sunlight when the baby's skin turns yellowish. (129) $82 \%$ of the mothers are applied 'Kajal' on baby's face to prevent bad eye. (92) $59 \%$ of the mothers are practicing a belief that "empty cradle should not be moved".

Interpretation and conclusion: Findings of the study revealed that there is a strong relationship between the demographic variables (type of family and religion) and cultural practices and beliefs on newborn care among mothers. Periodical health education regarding do's and don'ts of newborn care should be conducted in postnatal ward, which will definitely minimize the unhealthy traditional practices.

Key words: Cultural practices, Beliefs, Newborn care, Mother.

\section{Introduction :}

Cultural and traditional practices, values and beliefs play an important role in the medical attention-seeking behavior of postpartum mothers as well as in newborn babies during the postnatal period. ${ }^{1}$

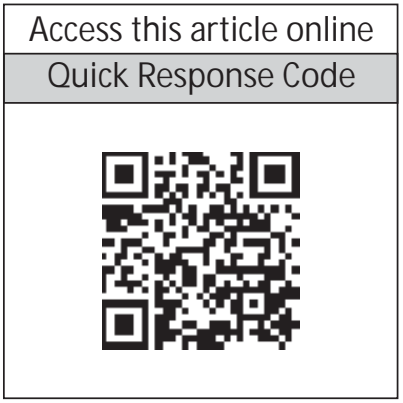

There are various traditional and cultural practices followed which affect the newborn. A family which mirrors values, traditions, customs and beliefs, i.e. culture of a society to which it belongs, plays an important role in physical, psychological, social development and health in children. ${ }^{2}$

Newborn mortality is one of the world's neglected health area. As most of births and deaths occur outside any established health care facility, reduction in neonatal mortality may depend significantly on interventions involving promotion or adaptation of traditional care behaviors practiced in the home. Feeding of colostrum, timing of initiation and duration of breastfeeding, umbilical cord care, and measures taken to prevent hypothermia of the newborn are important factors in health and survival during the neonatal period. ${ }^{1}$ 
Some of the practices followed are first bath of the baby by adding 40 stones or placing a needle to bathwater of babies, not cutting babies $1^{\text {st }}$ nail until the babies were 40 days old, swaddling, removal of umbilical cord, Evil eye, time of breast feeding within one hour of delivery or 8 hours after delivery, wrapping babies with yellow fabric or using lamps with yellow light etc in case of jaundice. ${ }^{2}$

The mothers who are not equipped with sufficient knowledge about newborn care and using traditional child care methods may sometimes cause harm to their newborn and even cause handicaps in them. ${ }^{2}$

In our community women receive information from family members, elders and traditional birth attendants. Hence, these groups, expectant mothers and mothers of newborns should be targeted with educational messages. Newborn care, similar to other human behaviors, is influenced by cultural beliefs. Hence exploration of cultural beliefs and practices of newborn care is essential. ${ }^{1}$

\section{Materials and Methods:}

The major task of the researcher was to develop an instrument that accurately and precisely measures the variables of interest. Data collection tools were the procedures or instruments used by the researcher to observe or measure the key variable in the research problem. Since the purpose of the study was to identify the cultural practices and beliefs on newborn care among mothers, a structured dichotomous questionnaire was prepared. The samples were selected by purposive sampling method.

The data was collected from Justice K.S. Hegde Charitable Hospital, M angalore. To conduct the study in the hospital, prior permission was obtained from higher authorities. Mothers were provided a comfortable area and they were informed that the main aim of the study is to assess the cultural practices and beliefs on newborn care. Consent was obtained from the mothers and each mothers were given 10-15 minutes to give appropriate response. The reliability of the tool was tested using Chronbach's Alpha and the value was 0.72 and the tool was found to be reliable. The period of data collection for the study was from $1 / 1 / 2013$ to $30 / 4 / 2013$. The demographic data and structured dichotomous questionnaire was given to the mothers to collect the data. The data was collected and recorded systematically of each subject and organized in a way that facilitates computer entry.

\section{Results:}

\section{Section I}

\section{Description of demographic characteristics}

Socio demographic variables of mothers revealed that out of 157 mothers, majority (72) $46 \%$ were in the age group of 26-30 years, (89) 57\% belonged to nuclear family, (89) $57 \%$ were from Hindu family, (32) $20 \%$ had SSLC qualification, (95) $61 \%$ of them were home makers, (83) $53 \%$ were having 1 child, (56) $36 \%$ had monthly income between Rs18,36215,187 , and (85) $54 \%$ of mothers duration of marital life was below 5 yrs.

\section{Section II}

Assessment of cultural practices and beliefs related to new born care among mothers

\section{Cultural practices and beliefs regarding bath}

The cultural practices and beliefs regarding bath revealed that highest percentage (149) $95 \%$ of the mothers massaged the baby with oil before bath and the lowest percentage (5) $3 \%$ gave bath to the baby with milk and (5) $3 \%$ added a gold coin to the bath water of the baby.

\section{Cultural practices and beliefs regarding feeding}

The cultural practices and beliefs regarding feeding revealed that the highest percentage (83) $53 \%$ of the mothers gave home remedies for digestion and the lowest percentage (16) $10 \%$ of the mothers fed baby with milk mixed with "kumkumkesar".

\section{Cultural practices and beliefs related to umbilical cord care}

The cultural practices and beliefs related to umbilical cord care revealed that the highest percentage (87) $55 \%$ of the mothers applied ashes or soot or powder or dry cow dung on the umbilical cord of the baby and the lowest percentage (8) $5 \%$ made the fathers to place his fore finger 
on the baby's umbilical cord to invert it if the umbilical cord is not inverted.

Cultural practices and beliefs related to care during jaundice

The cultural practices and beliefs in care during jaundice revealed that the highest percentage (115) $73 \%$ of the mothers exposed the baby to sun light when the baby's skin turns yellow and the lowest percentage (10) $6 \%$ of the mothers dressed the baby with yellow clothes during jaundice.

\section{Cultural practices and beliefsto prevent evil eye}

The cultural practices and beliefs to prevent evil eye revealed that the highest percentage (129) $82 \%$ of the mothers applied Kajal on the baby'sface to prevent bad eye and lowest percentage (99) 63\% tied a thread with panchaloham to the baby.

\section{Other cultural practices and beliefs related to newborn care}

Regarding the other cultural practices and beliefs, the highest percentage (92) $59 \%$ of the mothers believe that empty cradle should not be moved and the lowest percentage (5) $3 \%$ of the mothers placed the umbilical cord blood in baby's mouth and spread over the back.

\section{Section III}

Association between the cultural practices and beliefs related to newborn care with the selected demographic variables.

One way ANOVA was performed to associate the cultural practices and beliefs with the selected demographic variables. The results showed that there is a difference in mean total score of the cultural practices across various types of family and Religion at $5 \%$ level of significance. All other variables there is no difference in the mean total score. There is a association between the type of family and religion with the cultural practices and beliefs on newborn care. So in this study the hypothesis is accepted that is "there will be significant association between cultural practices and beliefs related to newborn care and selected demographic variables"

\begin{tabular}{|c|c|c|}
\hline \multirow{2}{*}{\multicolumn{3}{|c|}{\begin{tabular}{|l|l|l|} 
DEM OGRAPHIC VARIABLES & FREQUENCY & PERCENTAGE (\%) \\
Age in years &
\end{tabular}}} \\
\hline & & \\
\hline$<25 y r s$ & 66 & 42 \\
\hline 26-30yrs & 72 & 46 \\
\hline$>30 \mathrm{yrs}$ & 19 & 12 \\
\hline \multicolumn{3}{|l|}{\begin{tabular}{|l|} 
Type of family \\
\end{tabular}} \\
\hline Nuclear family & 89 & 57 \\
\hline Joint family & 64 & 41 \\
\hline Extended family & 4 & 2 \\
\hline \multicolumn{3}{|l|}{ Religion } \\
\hline Hindu & 89 & 57 \\
\hline Christian & 48 & 30 \\
\hline Muslim & 20 & 13 \\
\hline \multicolumn{3}{|l|}{ Education } \\
\hline No formal education & 31 & 20 \\
\hline Higher primary & 34 & 22 \\
\hline SSLC & 32 & 20 \\
\hline PUC & 29 & 18 \\
\hline Graduation and above & 31 & 20 \\
\hline \multicolumn{3}{|l|}{ Occupation } \\
\hline Home maker & 95 & 61 \\
\hline Daily wages & 21 & 13 \\
\hline Government employee & 8 & 5 \\
\hline Private employee & 33 & 21 \\
\hline \multicolumn{3}{|l|}{ Duration of married life } \\
\hline Below 5 years & 85 & 54 \\
\hline $6-10$ years & 39 & 25 \\
\hline $11-15$ years & 11 & 7 \\
\hline$>15$ years & 22 & 14 \\
\hline \multicolumn{3}{|l|}{ Number of children } \\
\hline 1 & 83 & 53 \\
\hline 2 & 61 & 39 \\
\hline 3 or more & 13 & 8 \\
\hline \multicolumn{3}{|l|}{ Monthly income } \\
\hline Equal to or more than & & \\
\hline Rs. 30,375 & 11 & 7 \\
\hline Rs.15,188-30,374 & 27 & 17 \\
\hline Rs.18,362-15,187 Rs & 56 & 36 \\
\hline Rs.7594-11,361 Rs & 38 & 24 \\
\hline Rs.4,556-7593 Rs & 11 & 7 \\
\hline Rs.1,521-4,555 Rs & 13 & 8 \\
\hline Equal to or less & & \\
\hline than Rs.1,520 & 1 & 1 \\
\hline
\end{tabular}

Table 1: Frequency and Percentage distribution of mothers according to demographic characteristics 
Cultural Practices And Beliefs Regarding Bath

\begin{tabular}{|l|l|c|c|}
\hline SL.NO & ITEM & FREQUENCY & PERCENTAGE (\%) \\
\hline 1 & Massaging the baby with oil before bath. & 149 & 95 \\
\hline 2 & Applying turmeric paste before bath. & 38 & 24 \\
\hline 3 & Giving bath to baby with milk. & 5 & 3 \\
\hline 4 & Adding 4l stones in the first bath water. & 5 & 4 \\
\hline 5 & Adding a gold coin to bath water of the baby. & 46 & 3 \\
\hline 6 & Two members are not supposed to give bath to the baby. & 64 & 41 \\
\hline 7 & Exposing baby over a "dhoopam" smoke after bath. & & 4 \\
\hline
\end{tabular}

Table 2: Frequency and Percentage distribution of mothers according to cultural practices and beliefs regarding bath.

Cultural Practices And Beliefs Regarding Feeding

\begin{tabular}{|c|c|c|c|}
\hline SL.NO & ITEM & FREQUENCY & PERCENTAGE (\%) \\
\hline 1 & Giving prelacteal feeds soon after birth like sugar water or honey or jaggery water. & 49 & 31 \\
\hline 2 & Feeding the baby with milk mixed with "kumkumkesar". & 16 & 10 \\
\hline 3 & Discarding the colostrum (first milk produced). & 25 & 16 \\
\hline 4 & Giving hot water to evacuate the stool. & 50 & 32 \\
\hline 5 & Giving home remedies for digestion like garlic or ginger or herbal leaves. & 83 & 53 \\
\hline
\end{tabular}

Table 3: Frequency and Percentage distribution of mothers according to cultural practices and beliefs regarding feeding

Cultural Practices And Beliefs Related To Umbilical Cord Care

\begin{tabular}{|l|l|c|c|}
\hline SL.NO & ITEM & FREQUENCY & PERCENTAGE (\%) \\
\hline 1 & Applying ashes or soot or powder or dry cow dung on the umbilical cord of the baby. & 87 & 55 \\
\hline 2 & Burrying the cord when it dries and falls. & 38 & 24 \\
\hline 3 & $\begin{array}{l}\text { Making the father to place his fore finger on the baby's umbilical cord to invert it } \\
\text { if the umbilical cord is not inverted. }\end{array}$ & 8 & 5 \\
\hline 4 & Applying heat to the umbilical cord to make it dry. & 15 & 10 \\
\hline
\end{tabular}

Table 4: Frequency and Percentage distribution of mothers according to cultural practices and beliefs related to umbilical cord care

Cultural Practices And Beliefs Related To Care During Jaundice

\begin{tabular}{|l|l|c|c|}
\hline SL.NO & ITEM & FREQUENCY & PERCENTAGE (\%) \\
\hline 1 & Exposing the baby to sun light when the baby's skin turns yellow. & 115 & 73 \\
\hline 2 & Giving sugar water to the baby during jaundice. & 17 & 11 \\
\hline 3 & Dressing the baby with yellow clothes during jaundice. & 10 & 6 \\
\hline
\end{tabular}

Table 5: Frequency and Percentage distribution of mothers according to cultural practices and beliefs related to care during jaundice

Cultural Practices And Beliefs To Prevent Evil Eye

\begin{tabular}{|l|l|c|c|}
\hline SL. NO. & ITEM & FREQUENCY & PERCENTAGE(\%) \\
\hline 1. & Applying kajal on the baby's face to prevent bad eye & 129 & 82 \\
\hline 2. & Tying black thread or bangles to the baby's hand or leg to prevent bad eye. & 104 & 66 \\
\hline 3. & Tying a thread with panchaloham to the baby. & 99 & 63 \\
\hline
\end{tabular}

Table 6: Frequency and Percentage distribution of mothers according to cultural practices and beliefs to prevent evil eye.

Other Cultural Practices And Beliefs Related To Newborn Care

\begin{tabular}{|c|c|c|c|}
\hline SL.NO & ITEM & FREQUENCY & PERCENTAGE(\%) \\
\hline 1 & Removing coated tongue by using a cloth soaked in baby's urine. & 47 & 30 \\
\hline 2 & I accept "empty cradle should not be moved". & 92 & 59 \\
\hline 3 & Baby is not allowed to be taken out after $6 \mathrm{pm}$. & 79 & 50 \\
\hline 4 & "Baby's cloth should not be placed outside at night". & 79 & 50 \\
\hline 5 & Place the first stool of the baby under the carpet. & 9 & 6 \\
\hline 6 & Umbilical cord blood is placed in baby's mouth and spread over the back. & 5 & 3 \\
\hline 7 & "Not cutting the baby's nail until the baby is 40 days old". & 44 & 28 \\
\hline
\end{tabular}

Table 7: Frequency and Percentage distribution of mothers related to other cultural practices and beliefs related to newborn care 
Association Between The Cultural Practices And Beliefs Related To Newborn Care With The Selected Demographic Variables.

\begin{tabular}{|c|c|c|c|c|c|c|}
\hline DEM OGRAPHICVARIAE & LES & NO & MEAN & SD & Fvalue & PValue \\
\hline Type of family & Nuclear & 89 & 9.22 & 3.97 & 5.932 & $0.003 *$ \\
\hline & Joint & 64 & 9.48 & 3.56 & & \\
\hline & Extended & 4 & 16.00 & 5.72 & & \\
\hline Religion & Hindu & 89 & 10.41 & 4.38 & 6.123 & $0.003 *$ \\
\hline & Christian & 48 & 8.06 & 3.06 & & \\
\hline & M uslim & 20 & 9 & 2.79 & & \\
\hline Education & No formal education & 31 & 9.19 & 3.91 & 0.571 & 0.684 \\
\hline & Higher primary & 34 & 10.14 & 4.71 & & \\
\hline & SSLC & 32 & 8.78 & 3.08 & & \\
\hline & PUC & 29 & 9.79 & 3.56 & & \\
\hline & Graduation and above & 31 & 9.58 & 4.37 & & \\
\hline Occupation & Home maker & 95 & 9.92 & 4.13 & 0.833 & 0.506 \\
\hline & Daily wages & 21 & 8.66 & 2.35 & & \\
\hline & Govt. Employees & 8 & 8.25 & 3.61 & & \\
\hline & Private employees & 33 & 9.06 & 4.38 & & \\
\hline Duration of marital life & Below 5yrs & 85 & 9.55 & 3.87 & 1.266 & 0.288 \\
\hline & 6-10yrs & 39 & 10.25 & 4.67 & & \\
\hline & 11-15yrs & 11 & 8.90 & 3.85 & & \\
\hline & Above 15yrs & 22 & 8.27 & 2.76 & & \\
\hline Monthly income & Equal to or more than $30,375 \mathrm{rs}$ & 11 & 10.18 & 5.30 & 1.825 & 0.098 \\
\hline & $15,188-30,374 \mathrm{rs}$ & 27 & 8.51 & 3.93 & & \\
\hline & $18,362-15,187 \mathrm{rs}$ & 56 & 9.67 & 4.16 & & \\
\hline & $7,594-11,361 \mathrm{rs}$ & 38 & 8.68 & 2.84 & & \\
\hline & $4,556-7,593 r s$ & 11 & 9.72 & 2.76 & & \\
\hline & $1,521-4,555$ rs & 13 & 12.38 & 4.78 & & \\
\hline & Equal to or less than 1,520 rs & 1 & 10.00 & -- & & \\
\hline
\end{tabular}

$*$ (Indicates significant)

Table: 8 : Association between the cultural practices and beliefs with selected demographic variables

\section{Discussion :}

Socio demographic variables of mothers revealed that out of 157 mothers, majority (72) $46 \%$ were in the age group of 26-30 years, (89) $57 \%$ belong to nuclear family, (89) $57 \%$ were from Hindu family, (32) $20 \%$ had SSLC qualification, (95) $61 \%$ of them were home makers, (83) $53 \%$ were having 1 child, (56) $36 \%$ had monthly income between Rs18,36215,187 , and (85) $54 \%$ of mothers duration of marital life is less than 5 years.

In this study majority $85 \%$ of mothers applied Kajal on the baby'sface to prevent evil eye. According to the descriptive study conducted in Chandigarh revealed that out of 226 mothers who had children below 3 months practice of applying Kajal was prevalent in $94.7 \%$ in slums and $28.3 \%$ in urban areas ${ }^{3}$.

Majority $95 \%$ of mothers massaged the baby with oil before bath. According to the study conducted in Rawalpindi district, Pakistan, out of 100 mothers who were having baby of 6 months age, it was found that oil massage was a frequent practice in $61 \%$ of babies ${ }^{4}$.

In this study $31 \%$ of mothers gave prelacteal feeds soon after birth. According to the descriptive study conducted in Civil Hospital Ahmedabad, among 435 mothers it was found that about $66.2 \%$ of mothers offered boiled water as a first feed ${ }^{5}$. And according to the qualitative study conducted in 6 urban slum areas of Dhaka, Bangladesh, among 18 recently delivered mothers it was found that $40 \%$ of women gave honey while $16 \%$ of women gave sugar water soon after birth ${ }^{6}$.

\section{Conclusion:}

The study was conducted under certain objectives to assess the cultural practices and beliefs on newborn care 
among mothers and to associate it with demographic variables.

Every society has its own traditional beliefs and practices related to baby care. Beliefs in super natural power that is holy rituals, salvation offerings and sacrifices are applied at different stages of life from birth to death. There are many such practices, rituals, beliefs and offerings which either protect or harm the health of the baby'. The study enabled the researchers to identify the cultural practices and beliefs on newborn care followed by the mothers. Help from the authorities and subjects made the study fruitful and interesting.

\section{Acknowledgement:}

Our sincere thanks to Nitte University for funding this research project and supporting us in every step during the process. We also thank Mr. Sanal, Statistician, KSHEM A, Mangalore, for the guidance provided related to analysis of the study.

\section{References:}

1. Dorland's Medical Dictionary for health consumers. 2007. Available from: www.thefreedictionary.com/newborn

2. Datta Parul. Pediatric nursing.J aypee publishers.New Delhi; 2007.

3. Madhu k, ChowdarySriram, Ramesh Masthi. Breastfeeding practices and newborn care in rural areas. Indian J community med. 2009 july; 34(3): 243-46. Available from :www.biomedcentral.com/14712393/9/54

4. TasneemAffzal, AfzalSaeed. Pattern of harmfull practices towards the newborn in a Pakistani community. Pakistan armed forces medical journal 2010. Available fromwww.pafmj.org/showdetails. php?id $=356 \& \mathrm{t}=0$

5. Postpartum,carelndianstyle.Availablefrom:http://yourkidand you.blogspot.in/2012/02/postpartum-care-indian-style.html

6. Allisyn C M oran, Nuzhat Choudhury. Newborn care practices among slum dwellers in Dhaka, Bangladesh: a quantitative and qualitative exploratory study.BM CPregnancy and Childbirth 2009, 9:54. Available from www.biomedcentral.com/1471-2393/9/54.

7. Swain Dharitri. Cultural beliefs and practices in pregnancy and child birth in India. Journal of Nightingale Nursing Times 2010; June 6(3):2932. 